\title{
Aminofluoresceins vs Fluorescein: Ascertained New Unusual Features of Tautomerism and Dissociation of Hydroxyxanthene Dyes in Solution
}

Nikolay O. Mchedlov-Petrossyan, ${ }^{* 1}$ Tatyana A. Cheipesh, ${ }^{1}$ Sergey V. Shekhovtsov, ${ }^{1}$ Elena V. Ushakova $^{1}$, Alexander D. Roshal, ${ }^{1}$ Iryna V. Omelchenko ${ }^{2}$

${ }^{1}$ Department of Physical Chemistry, V. N. Karazin Kharkov National University, Kharkov, 61022, Ukraine

${ }^{2}$ Institute for Single Crystals (SSI), 60 Nauka avenue, Kharkov 61001, Ukraine

\section{Contents}

1. Absorption spectra of 5'-aminofluorescein at different DBU concentrations in DMSO

2. Absorption spectra of 4'- and 5'-aminofluorescein in benzoate buffer solutions in acetonitrile

3. Absorption spectra of fluorescein dyes in buffer solutions in DMSO

4. Determination of the $\mathrm{p} K_{\mathrm{a}}$ values of 5 '-aminofluorescein in 91 mas \% aqueous DMSO

5. Ionization of phenol red and 5'-aminofluorescein in DBU + triflic acid system in DMSO: specific interactions

6. ${ }^{1} \mathrm{H}$ NMR spectrum of 5 '-aminofluorescein in $\left(\mathrm{CD}_{3}\right)_{2} \mathrm{~S}=\mathrm{O}$

7. ${ }^{1} \mathrm{H}$ NMR spectrum of 4,5-dinitro methyl ether of fluorescein in $\left(\mathrm{CD}_{3}\right)_{2} \mathrm{~S}=\mathrm{O}$

8. Absorption spectra of 4,5-dinitro methyl ether of fluorescein in DMSO in the presence of 4,5-dinitrofluorescein admixture.

9. Preparative separation of 4,5-dinitro methyl ether of fluorescein and 4,5dinitrofluorescein via thin layer chromatogram.

10. The results of X-ray study of 4,5-dinitro methyl ether of fluorescein.

11. The 'titration curves' of fluorescein and 5'-aminofluorescein in DMSO.

\footnotetext{
${ }^{*}$ Correspondence to: N. O. Mchedlov-Petrossyan, V.N. Karazin Kharkov National University, 61022
} Kharkov, Ukraine, e-mail: nikolay.mchedlov@gmail.com 
1. Absorption spectra of 5 '-aminofluorescein at different DBU concentrations in DMSO

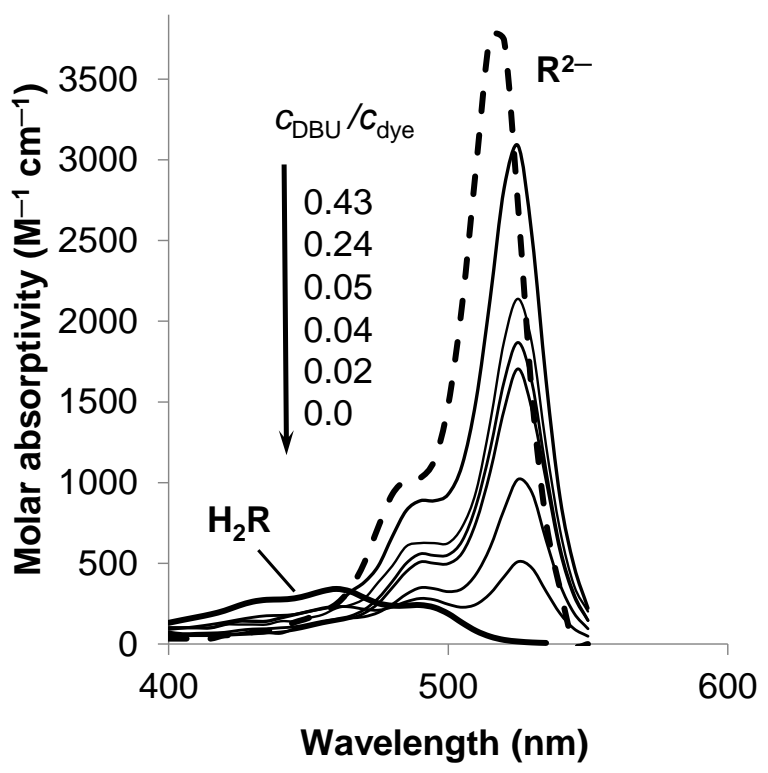

Fig. S1. Absorption spectra of 5'-aminofluorescein in DMSO under variation of DBU concentration. Spectra of neutral form, $\mathbf{H}_{2} \mathbf{R}$, were obtained in the presence of $0.10 \mathrm{M}$ benzoic acid. Dotted line: the spectrum of the dianion, absorptivity divided by 30 . 
2. Absorption spectra of 4'- and 5'-aminofluorescein in benzoate buffer solutions in acetonitrile

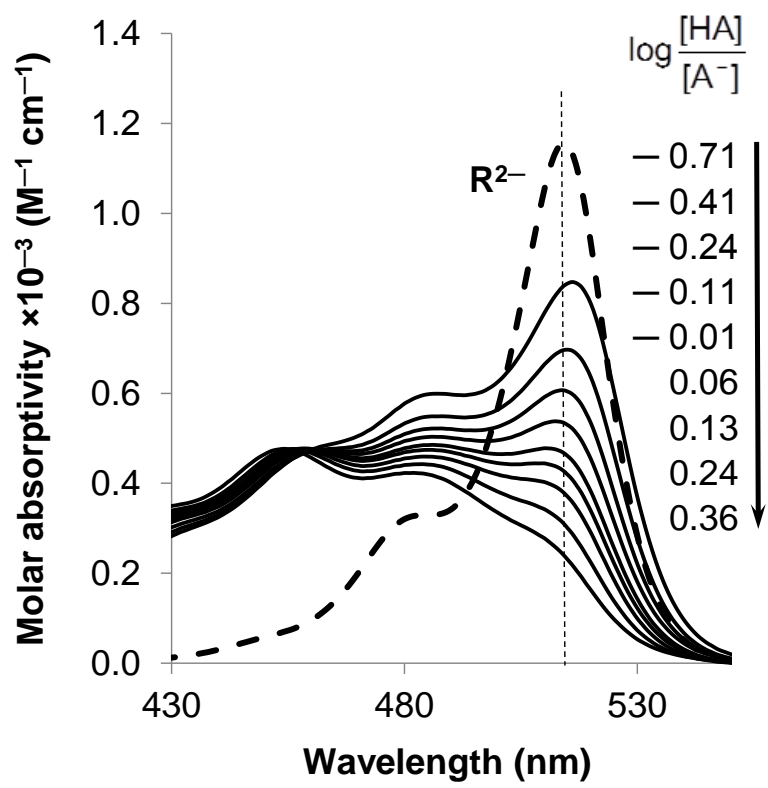

Fig. S2. Absorption spectra of 4'-aminofluorescein in acetonitrile with 2 vol \% DMSO; benzoate buffer solutions with different benzoic acid : potassium benzoate ratio. The spectrum of the dianion $\mathrm{R}^{2-}$ (absorptivities divided by 100) was obtained on addition of DBU.

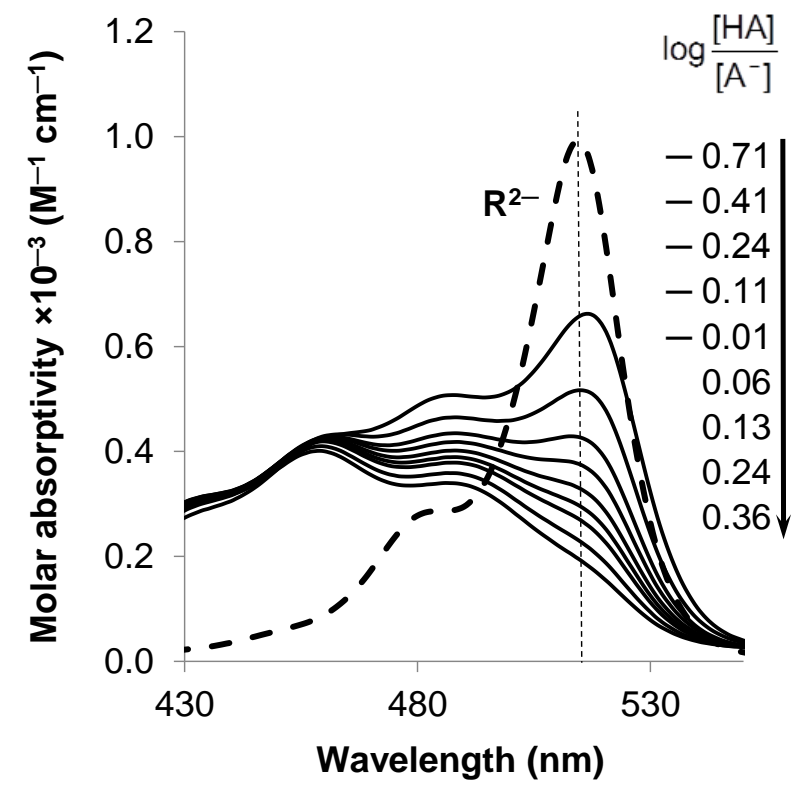

Fig. S3. Absorption spectra of 5'-aminofluorescein in acetonitrile with 2 vol \% DMSO; benzoate buffer solutions with different benzoic acid : potassium benzoate ratio. The spectrum of the dianion $\mathrm{R}^{2-}$ (absorptivities divided by 100) was obtained on addition of DBU. 
3. Absorption spectra of fluorescein dyes in buffer solutions in DMSO

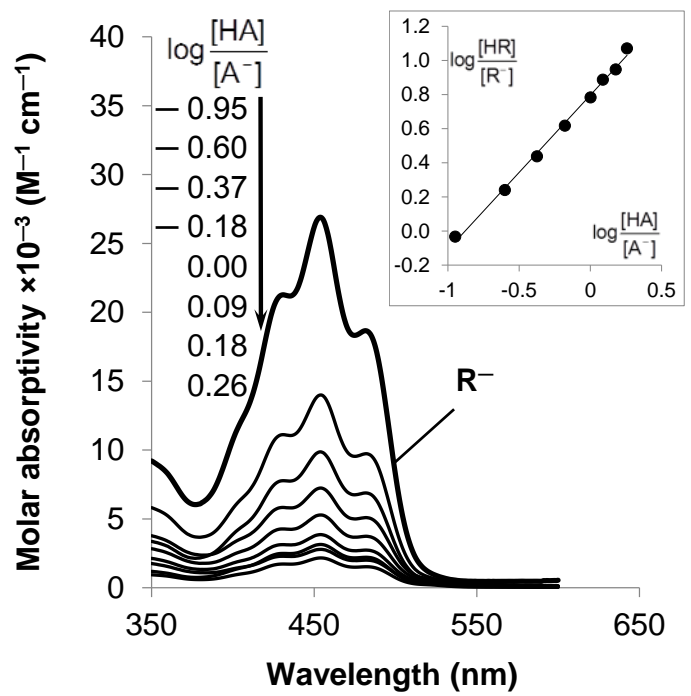

Fig. S4. Methyl ether of fluorescein in 4-aminobenzoate buffer solutions.

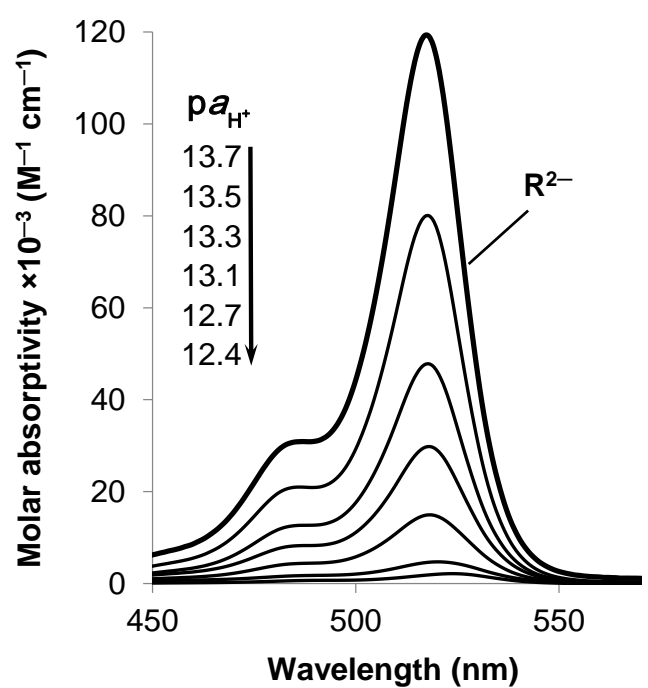

Fig. S5. Absorption spectra of 5'-aminofluorescein in DMSO in 4-aminobenzoate buffer solutions.

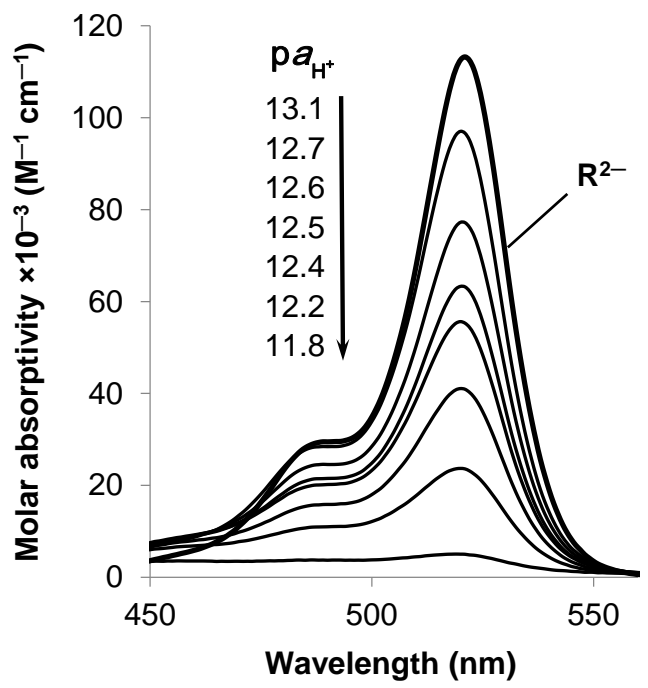

Fig. S6. Absorption spectra of fluorescein in DMSO in 4-aminobenzoate buffer solutions. 
4. Determination of the $\mathrm{p} K_{\mathrm{a}}$ values of 5 '-aminofluorescein in 91.3 mas $\%$ aqueous DMSO

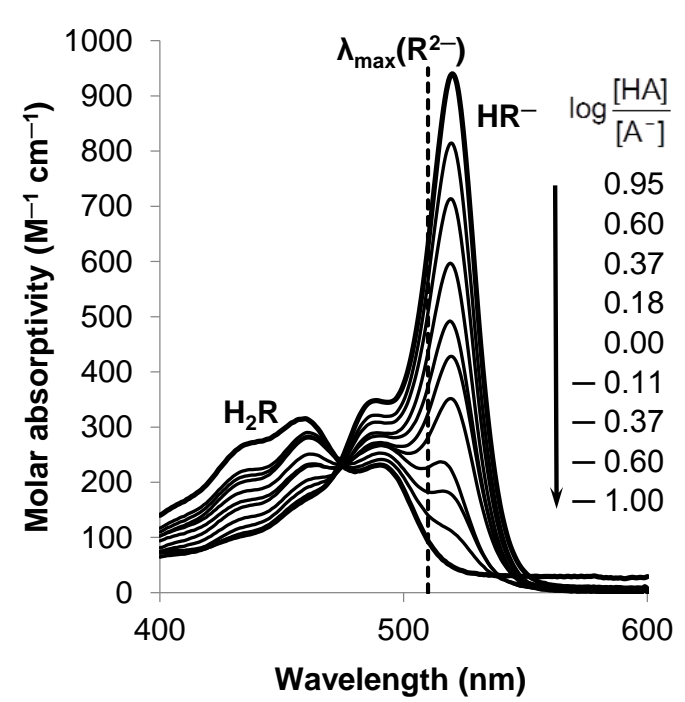

a)

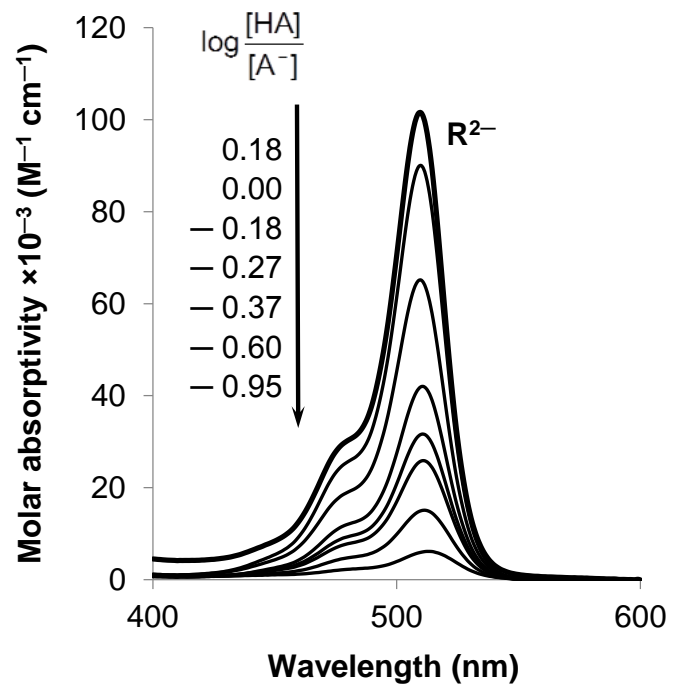

b)

Fig. S7. Absorption spectra of 5'-aminofluorescein in 91.3 mas \% aqueous DMSO; in benzoate buffer solutions (a) and in diethylbarbiturate buffer solutions (b). The spectra of the neutral, monoanionic, and dianionic forms were obtained in $0.002 \mathrm{M}$ salicylic acid, $0.01 \mathrm{M}$ potassium benzoate, and $0.005 \mathrm{M} \mathrm{NaOH}$ solutions, respectively. Ionic strength in buffer solutions: $0.005 \mathrm{M}$.

The thermodynamic $\mathrm{p} K_{\mathrm{HA}}$ values of buffer acids are 8.05 (benzoic acid) and 10.77 (diethylbarbituric acid). The thermodynamic values of the dye are as follows: $\mathrm{p} K_{a 1}=8.21 \pm$ $0.14, \mathrm{p} K_{a 2}=10.69 \pm 0.14$ (ionic activity coefficients were calculated using a version of the second approach of the Debye-Hückel equation).

In $91.3 \%$ DMSO, the $\lambda_{\max }, \mathrm{nm}\left(E_{\max } \times 10^{-3}, \mathrm{~L} \times \mathrm{mol}^{-1} \times \mathrm{cm}^{-1}\right)$ values are as follows:

Dianion, $\mathrm{R}^{2-}: 510$ (102);

Monoanion, $\mathrm{HR}^{-}$: 520 (0.91);

Neutral, $\mathrm{H}_{2} \mathrm{R}: 460$ (0.32), 488-492 (0.23). 


\section{Ionization of phenol red and $5^{\prime}$-aminofluorescein in DBU + triflic acid system in DMSO: specific interactions}

The dianionic form $\mathrm{R}^{2-}$ of the dye phenol red associates with the protonated DBU species, $\mathrm{DBUH}^{+}$. The dye solution with concentration $1.4 \times 10^{-5} \mathrm{M}$ with excess of DBU (ca. $0.08 \mathrm{M}$ ) was titrated with the triflate acid, Fig. S8. Assuming that in the end of titration the complete conversion of the dye into the associate is reached, the indices of the association constant may be estimated via the below formula:

$$
\mathrm{p} K_{\text {ass }}=-\log \left(\frac{A-A_{R^{2-}}}{A_{\text {ass }}-A} \cdot c\left(\mathrm{DBUH}^{+}\right)\right)
$$

Here $A_{R^{2-}}, A_{\text {ass }}$, and $A$ correspond to the absorbances of the free dye, the associate $\mathrm{DBUH}^{+} \mathrm{R}^{2-}$, and at current triflate acid concentration, respectively, $c\left(\mathrm{DBUH}^{+}\right)$is the concentration of the protonated DBU molecules, which is equated to the concentration of $\mathrm{CF}_{3} \mathrm{SO}_{3} \mathrm{H}$. A value of $2.73 \pm 0.01$ was determined.

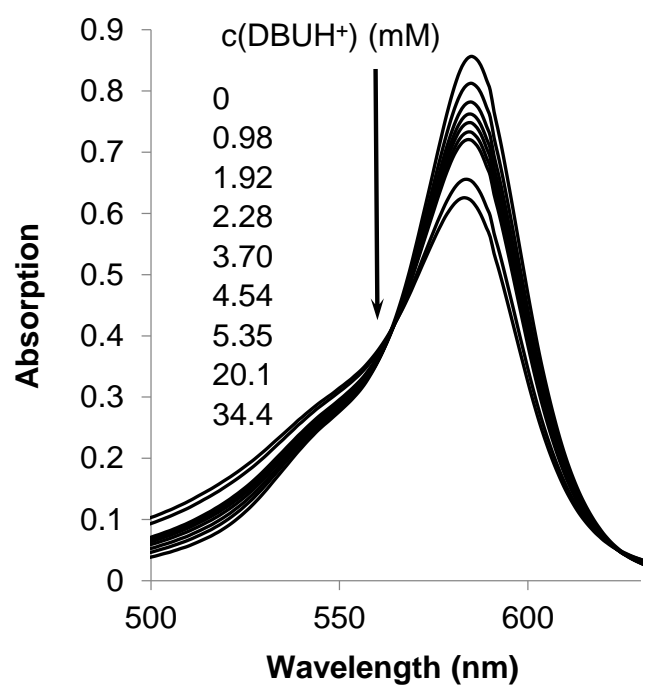

Fig. S8. Absorption spectra of phenol red in DMSO at various $\mathrm{DBUH}^{+}$concentrations.

For 5'-aminofluorescein the effects in $\mathrm{DBU}+\mathrm{CF}_{3} \mathrm{SO}_{3} \mathrm{H}$ system are qualitatively similar, Fig. S9. However, the alterations of the spectra are too modest to be used for estimating the equilibrium constant. 


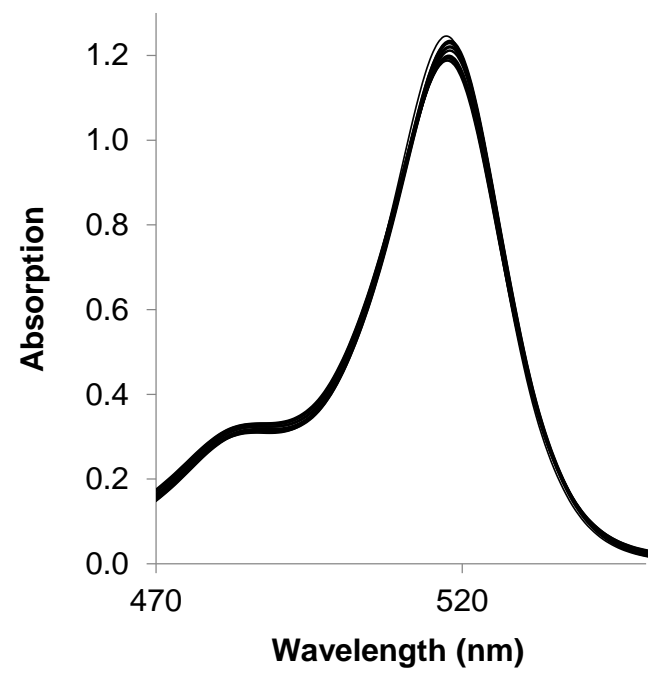

Fig. S9. Absorption spectra of 5'-aminofluorescein in DMSO at various $\mathrm{DBUH}^{+}$concentrations; the highest value of $c\left(\mathrm{DBUH}^{+}\right)$is $5 \mathrm{mM}$. 


\section{6. ${ }^{1} \mathrm{H}$ NMR spectrum of 5 '-aminofluorescein in $\left(\mathrm{CD}_{3}\right)_{2} \mathrm{~S}=\mathrm{O}$}
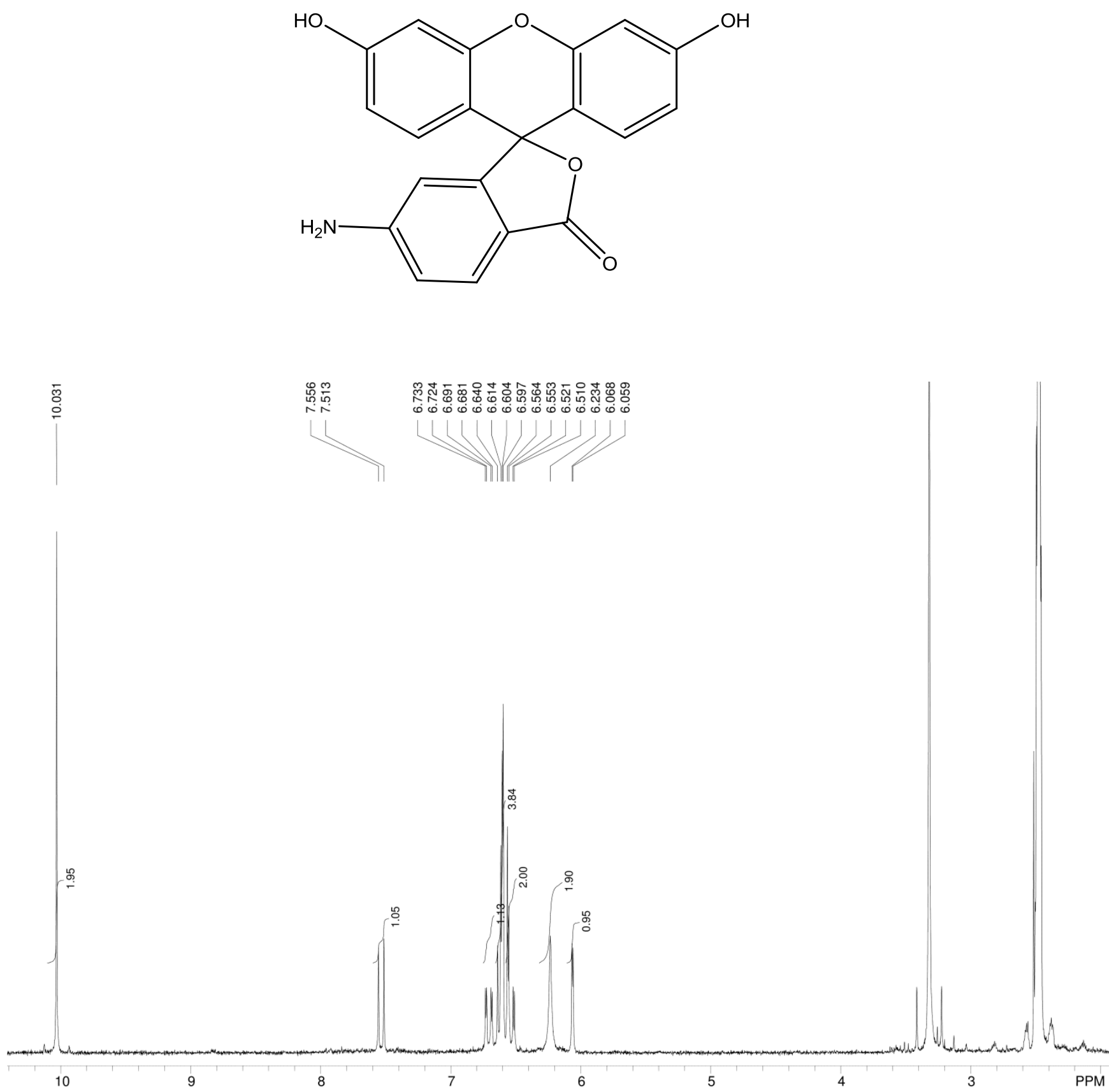

Fig. S10. ${ }^{1} \mathrm{H}-\mathrm{NMR}$ spectrum of $5^{\prime}$-aminofluorescein in $\left(\mathrm{CD}_{3}\right)_{2} \mathrm{SO}, \delta / \mathrm{ppm}: 10.031(2 \mathrm{H}, \mathrm{s}, \mathbf{O H})$, 7.535 (1H, d, J=8.4 Hz, 3'), 6.706 (1H, dd, $J=8.4 \mathrm{~Hz}, J=1.8 \mathrm{~Hz}, 4$ '), 6.618 (2H, d, $J=8.7 \mathrm{~Hz}, \mathbf{8 , 1})$, $6.610(2 \mathrm{H}, \mathrm{d}, J=2.1 \mathrm{~Hz}, \mathbf{5}, \mathbf{4}), 6.537(2 \mathrm{H}, \mathrm{dd}, J=8.7 \mathrm{~Hz}, J=2.1 \mathrm{~Hz}, \mathbf{2 , 7}), 6.234\left(2 \mathrm{H}, \mathrm{s}, \mathbf{N H}_{2}\right), 6.036$ (1H, d, J=1.8 Hz, 6'). 
7. ${ }^{1} \mathrm{H}$ NMR spectrum of methyl ether of 4,5-dinitrofluorescein in $\left(\mathrm{CD}_{3}\right)_{2} \mathrm{~S}=\mathrm{O}$<smiles>COc1ccc2c(c1[N+](=O)[O-])Oc1c(ccc(O)c1[N+](=O)[O-])C21OC(=O)c2ccccc21</smiles>

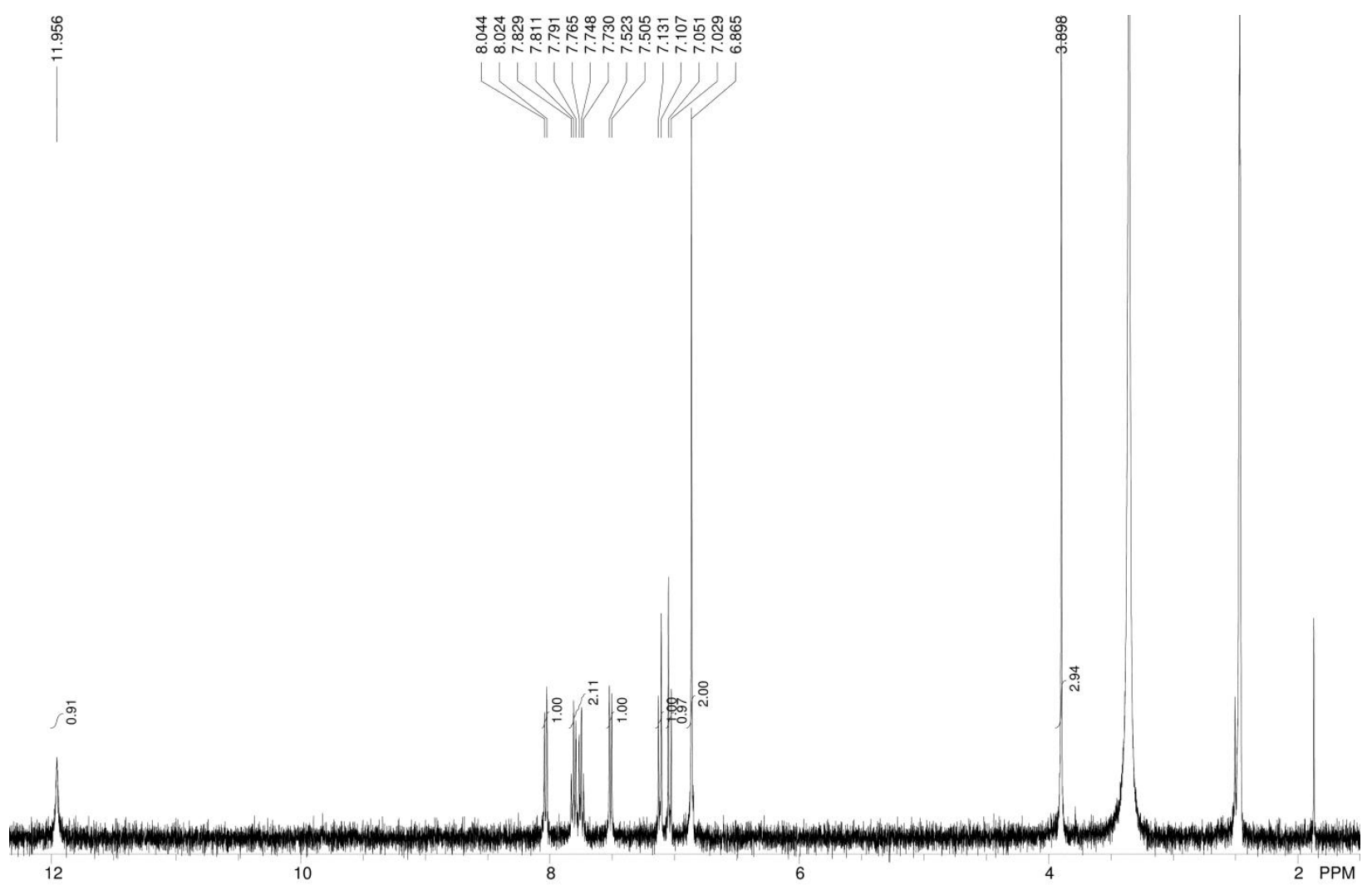

Fig. S11. ${ }^{1} \mathrm{H}-\mathrm{NMR}$ spectrum of methyl ether of 4,5-dinitrofluorescein in $\left(\mathrm{CD}_{3}\right)_{2} \mathrm{SO}, \delta / \mathrm{ppm}$ : 11.956 (1H, s, OH), 8.035 (1H, d, J=7.3 Hz, 3'), 7.840-7.720 (2H, m, J=7.3 Hz, 4', 5'), 7.515 $(1 \mathrm{H}, \mathrm{d}, J=7.3 \mathrm{~Hz}, \mathbf{6}), 7.120(1 \mathrm{H}, \mathrm{d}, J=9.1 \mathrm{~Hz}, \mathbf{1}), 7.039(1 \mathrm{H}, \mathrm{d}, J=9.1 \mathrm{~Hz}, 2), 6.865(2 \mathrm{H}, \mathrm{s}, \mathbf{7}, \mathbf{8})$, $3.898\left(3 \mathrm{H}, \mathrm{s}, \mathbf{C H}_{\mathbf{3}} \mathbf{O}\right)$. 
8. Absorption spectra of 4,5-dinitro methyl ether of fluorescein in DMSO in the presence of 4,5-dinitrofluorescein admixture

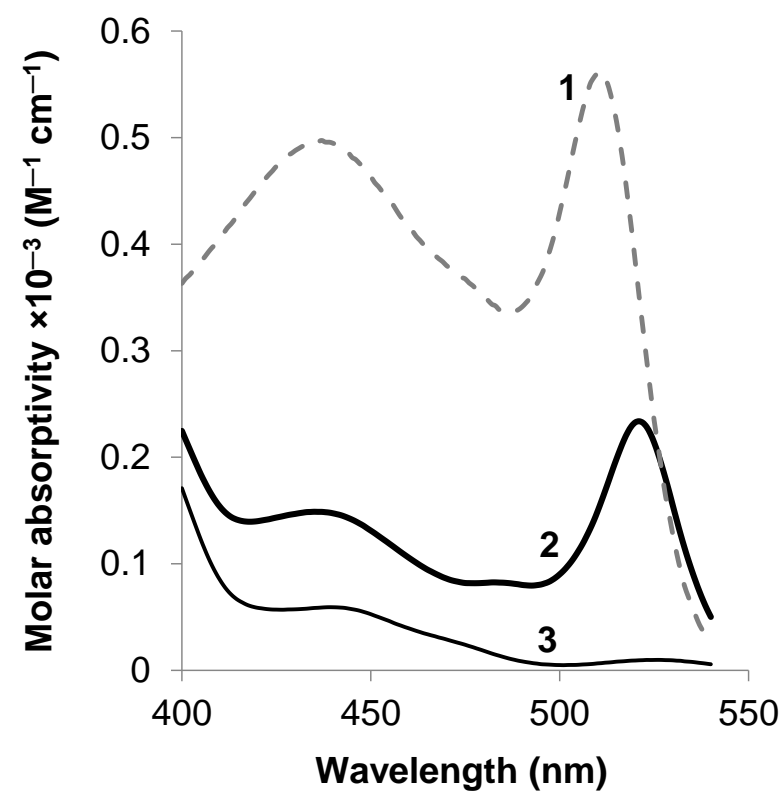

Fig. S12. Absorption spectra of methyl ether of 4,5-dinitrofluorescein, with admixture of 4,5dinitrofluorescein, in DMSO: with $\approx 0.05 \mathrm{M} \mathrm{DBU} \mathrm{(1;} \mathrm{molar} \mathrm{absorptivities} \mathrm{decreased} \mathrm{5-fold);}$ without additives (2); and with $\approx 1 \mathrm{M} \mathrm{H}_{2} \mathrm{SO}_{4}$ (3). Taking into account the molar absorptivity of the $\mathrm{R}^{2-}$ anion of 4,5-dinitrofluorescein (about $10^{5} \mathrm{M}^{-1} \mathrm{~cm}^{-1}$ ), the admixture does not exceed $1 \%$. 


\section{Preparative separation of 4,5-dinitro methyl ether of fluorescein and 4,5- dinitrofluorescein via thin layer chromatogram}

Even the sample numerously re-crystallized from glacial acetic acid contained small traces of 4,5-dinitrofluorescein, which manifests themselves in appearance of an absorption band at 526 $\mathrm{nm}$ in DMSO, where the main compound is almost colorless (see Supporting Information). This band should be ascribed to the $\mathrm{HR}_{\mathrm{P}}{ }^{-}$tautomer of 4,5-dinitrofluorescein; adding $0.05 \mathrm{M} \mathrm{DBU}$ results in a shift of the maximum toward $511 \mathrm{~nm}$, caused by conversion of $\mathrm{H}_{2} \mathrm{R}$ and $\mathrm{HR}^{-}$species into the $\mathrm{R}^{2-}$ dianion. The moving off 4,5-dinitrofluorescein was possible only by preparative thin-layer chromatography.

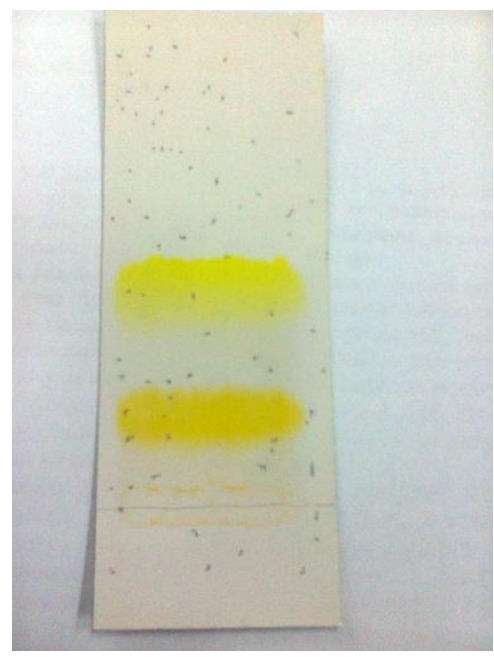

Fig. S13. Thin-layer chromatogram of the mixture of methyl ether of 4,5-dinitrofluorescein, with admixture of 4,5-dinitrofluorescein; Silufol plates, eluent benzene - acetone (4 : 1). Top: methyl ether of 4,5-dinitrofluorescein; bottom: 4,5-dinitrofluorescein. 


\section{The results of X-ray study of 4,5-dinitro methyl ether of fluorescein}

In the asymmetric part of the unit cell, there are two molecules of the 4,5-dinitro fluorescein methyl ether in the neutral lactone form with slightly different geometrical parameters (Figure 1). The pyran ring of the xanthene moiety is planar in one molecule (to within $0.01 \AA$ ) but adopts flattened boat conformation in the other one (atoms $\mathrm{C}(1)^{\prime}$, and $\mathrm{O}(1)$ ' deviate from the plane of other ring atoms on 0.23 and $0.12 \AA$, respectively). The non-planar pyran ring is more typical for the fluorescein derivatives (mean deviation of the quaternary $\mathrm{C}$ atom is $0.15 \AA .{ }^{1}$ Also, the $\mathrm{C}(1)-$ $\mathrm{O}(4)$ bond length is different in two molecules (1.489(7) $\AA$ in the first one and 1.525(7) $\AA$ in the second, while the mean value for such bonds is $1.508 \AA^{1}$ ). Those factors lead to the different molecular shape of the two molecules in the crystal: while the twist angles between xanthene and isobenzofuran moieties are similar and close to $90^{\circ}\left(91.8(1)^{\circ}\right.$ and $87.4(1)^{\circ}$, respectively), the fold angles are notably different $\left(17.8(2)^{\circ}\right.$ and $1.1(2)^{\circ}$, respectively).

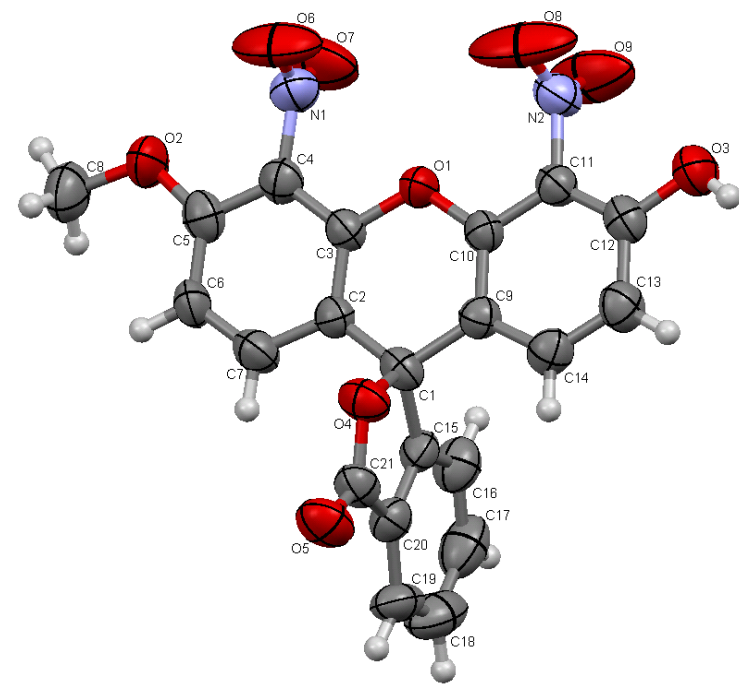

Fig. S14. Molecular structure of the 4,5-dinitro fluorescein methyl ether according to the X-ray diffraction data. Only one of the two symmetrically independent molecules is shown in the figure.

Surprisingly, the inclusion of the pyran oxygen into the cyclic conjugation is stronger in the non-planar ring: the $\mathrm{O}(1)^{\prime}-\mathrm{C}(3)^{\prime}$ and $\mathrm{O}(1)^{\prime}-\mathrm{C}(10)^{\prime}$ bonds of 1.356(8) and 1.354(9) $\AA$ are shorter than corresponding bonds in the first molecule (1.375(7) and 1.372(7) $\AA$ ), and also than mean 
values for fluorescein derivatives $(1.377 \AA) .{ }^{1}$ The $C(2)^{\prime}-C(3)^{\prime}$ and $C(9)^{\prime}-C(10)$ ' bonds $(1.395(8)$ and $1.396(8) \AA)$ are consequently longer in the second molecule that in the first one $(1.380(8)$ and $1.372(8) \AA$ ), while the mean value equal to $1.386 \AA$. That is directly related to the pronounced bond alternating in the $\mathrm{C}(9) \ldots \mathrm{C}(14)$ ring with hydroxyl substituent in the first molecule and the absence of such effect in the second one. However, the $\mathrm{C}_{\mathrm{ar}}-\mathrm{OH}$ bond lengths are very similar in both molecules $(1.350(8)$ and $1.352(8) \AA)$.

Nitro groups are rotated with respect to the plane of the xanthene moieties, more pronounced in the first molecule (angles are $84(1)^{\circ}$ and $\left.100(1)^{\circ}\right)$ and less in the second one $\left(67(1)^{\circ}\right.$ and $\left.68(1)^{\circ}\right)$. At the time, the $\mathrm{C}_{\mathrm{ar}}-\mathrm{NO}_{2}$ bond lengths depend on the ring type only: they are smaller in both methoxy substituted rings $(1.449(8)$ and $1.455(9) \AA$ ) but longer in hydroxyl substituted (1.471(8) and 1.47(1) $\AA$ ). The hydroxyl groups do not form the intramolecular hydrogen bonds with adjacent nitro groups as it was discovered previously in the structurally similar nitro derivatives of the phenolsulphonephtaleins ${ }^{2,3}$ but are involved in the intermolecular H-bonding with the carboxylic oxygen $\mathrm{O}(5)\left(\mathrm{H} \ldots \mathrm{O} 1.89 / 1.94 \AA\right.$, O-H... $\left.166^{\circ}\right)$. In the crystal, these bonds arrange molecules into helical chains along the (010) crystallographic direction.

\section{References}

(1) Groom, C. R.; Allen, F. H. The Cambridge structural database in retrospect and prospect. Angew. Chem. Int. Ed. 2014, 53, 662-671.

(2) Mchedlov-Petrossyan, N. O.; Roshchyna, K. V.; Shekhovtsov, S. V.; Eltsov, S. V.; Zozulia, O. S.; Omelchenko, I. V.; Shishkin, O. V. Revisiting tetranitrophenolsulfonephthalein. Color. Technol., 2015, 131, 236-244.

(3) Mchedlov-Petrossyan, N. O.; Laguta, A. N.; Shekhovtsov, S. V.; Eltsov, S. V.; Cheipesh, T. A.; Omelchenko, I. V.; Shishkin, O. V. 3,3'-Dinitrophenolsulphonephthalein: An acidbase indicator dye with unusual properties. Color. Technol. 2017, 133, 135-144. 
11. The 'titration curves' of fluorescein and 5'-aminofluorescein in DMSO

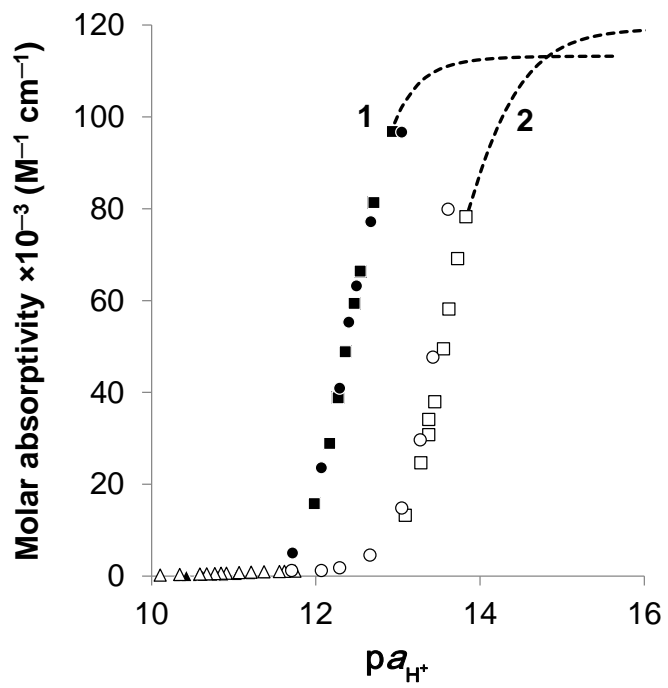

Figure S15. The 'titration curves', i.e., dependences of molar absorptivity at $\lambda_{\max }\left(\mathrm{R}^{2-}\right)$ of fluorescein (1) and 5'-aminofluorescein (2) on $\mathrm{p}_{\mathrm{H}^{+}}$; buffer systems: benzoate (triangles), $p$ aminobenzoates (circles), diethylbarbiturate (squares). Dotted lines: values calculated using the $\mathrm{p} K_{\mathrm{a} 1}$ and $\mathrm{p} K_{\mathrm{a} 2}$. 